\title{
Tingkat Keberterimaan Siswa Sekolah Menengah Atas di Kecamatan Padang Utara Kota Padang Terhadap Permainan Volscert
}

\author{
Alfio Restu Fernando, M. Sazeli Rifki, Endang Sepdanius ${ }^{7)}$
}

\begin{abstract}
ABSTRAK
Permainan volscert merupakan permainan bola besar yang dikembangkan untuk memenuhi kebutuhan masyarakat sebagai permainan dalam kegiatan rekreasi. Sebagai sarana rekreasi permaian volscert perlu diperkenalkan dikalangan sekolah. Untuk itu, penelitian ini bertujuan untuk melihat keberterimaan siswa Sekolah Menengah Atas di Kecamatan Padang Utara Kota Padang terhadap permainan volscert. Jenis penelitian ini adalah deskriptif. Populasi dalam penelitian ini berjumlah tujuh sekolah dengan jumlah siswa 3251 siswa. Sampel dalam penelitan ini diambil dengan teknik random sampling berjumlah 118 orang siswa dari dua sekolah menengah atas. Angket yang digunakan untuk mengumpulkan data menggunakan skala likert. Data dianalisis menggunakan rumus distribusi frekuensi dalam bentuk persentase. Berdasarkan hasil penelitian menunjukan bahwa tingkat keberterimaan siswa sekolah menengah atas di Kecamatan Padang Utara Kota Padang terhadap permainan volscert adalah baik. Hal ini ditunjukan dari data hasil penelitian dengan skor rata-rata 318.49 atau $82.72 \%$ termasuk dalam kategori baik.
\end{abstract}

Kata kunci : Olaharaga Volscert, Tingkat Keberterimaan, Siswa

\section{PENDAHULUAN}

Kemajuan suatu bangsa dapat diukur dengan kemajuan pendidikan bangsa tersebut.Melalui pendidikan manusia dapat berupaya memenuhi kebutuhan yang diperlukan dan mampu menghadapi tantangan hidup setiap saat. Pendidikan adalah salah satu bidang yang memegang peranan penting untuk membangun manusia seutuhnya.Untuk memperoleh pendidikan yang bermutu juga didukung oleh keadaan jasmani yang sehat atau yang sering kita kenal dengan kebugaran jasmani. Dengan memiliki jasmani yang sehat maka akan mampu melakukan seluruh aktifitas dengan baik. Disamping itu pendidikan jasmani juga dapat mengembangkan aktifitas jasmani yang mereka pilih dan mampu mengatasi emosional, tindak moral serta menanamkan pola hidup sehat dan lingkungan bersih dalam kehidupannya, sehingga membantu pencapaian tujuan pendidikan secara Nasional.

Pendidikan Jasmani merupakan bagian dari pendidikan yang bertujuan untuk mengembangkan aspek kebugaran jasmani, keterampilan gerak, dan tindakan moral.

7) Alfio Restu Fernando. Saat ini Mahasiswa Jurusan Kesehatan dan Rekreasi Fakultas Ilmu Keolahragaan Universitas Negeri Padang

7) M. Sazeli Rifki. Saat ini Dosen Jurusan Kesehatan dan Rekreasi Fakultas Ilmu Keolahragaan Universitas Negeri Padang

${ }^{7)}$ Endang Sepdanius. Saat ini Dosen Jurusan Kesehatan dan Rekreasi Fakultas Ilmu Keolahragaan Universitas Negeri Padang 
Pendidikan Jasmani juga bertujuan untuk mengenalkan kepada siswa tentang pola hidup sehat dan menjaga kebersihan lingkungan. Menurut (Dwiyogo, 2010:3) "Pendidikan Jasmani adalah aktivitas psikomotorik yang dilaksanakan atas dasar pengetahuan (kognitif) dan pada saat melaksanakannya akan terjadi perilaku pribadi yang terkait dengan sikap atau afektif (seperti kedisiplinan, kejujuran, percaya diri, ketangguhan) serta prilaku sosial (seperti kerjasama, saling menolong)".

Pengertian pembelajaran itu sendiri adalah proses yang diselenggarakan oleh guru untuk membelajarkan siswa dalam belajar bagaimana memperoleh dan memperoses pengetahuan, keterampilan, dan sikap (Dimyati dan Mudjiono, 2006: 157). Pendidikan Jasmani yang diajarkan di sekolah memiliki peranan sangat penting, karena dapat memberikan kesempatan kepada peserta didik untuk terlibat langsung dalam berbagai pengalaman belajar melalui aktivitas jasmani yang dilakukan secara sistematis. Pembekalan Pendidikan Jasmani di sekolah diperlukan untuk memberikan kesempatan siswa dalam membina pertumbuhan fisik dan pengembangan psikis yang lebih baik, seperti yang disebutkan oleh Husdarta (2009: 3) yaitu "Pendidikan Jasmani melibatkan aktivitas fisik dan kesehatan untuk menghasilkan perubahan holistic dalam kualitas individu, baik dalam hal fisik, mental serta emosional".

Salah satu materi yang ada dalam pendidikan jasmani adalah olahraga permainan. Menurut Roesdiyanto (2012: 33) "Permainan merupakan aktivitas kompetitif yang melibatkan skil fisik, strategi, dan kesempatan atau segala kombinasi dari elemenelemen tersebut". Sedangkan model permainan adalah prosedur yang dilakukan dengan mempergunakan atau tidak mempergunakan alat yang menghasilkan pengertian memberikan informasi, memberikan kesenangan dan dapat mengembangkan imajinasi anak.

Olahraga permainan yang biasa dialakukan disekolah adalah olahraga permainan bola besar. Permainan bola besar adalah salah satu cabang olahraga yang dilakukan secara berkelompok dengan menggunakan bola berdiameter lebih dari $50 \mathrm{~cm}$. Jenis olagraga yang dikategorikan permainan olahraga bola besar adalah, yaitu: (1) Sepak bola, (2) Bola voli, (3) Bola basket, dan (4) Sepak takraw

Dari hasil observasi yang peneliti lakukan di sekolah menengah atas di kota Padang, peneliti menemukan variasi olahraga permainan bola besar masih terbatas. Oleh

7) Alfio Restu Fernando. Saat ini Mahasiswa Jurusan Kesehatan dan Rekreasi Fakultas Ilmu Keolahragaan Universitas Negeri Padang

7) M. Sazeli Rifki. Saat ini Dosen Jurusan Kesehatan dan Rekreasi Fakultas Ilmu Keolahragaan Universitas Negeri Padang

${ }^{7)}$ Endang Sepdanius. Saat ini Dosen Jurusan Kesehatan dan Rekreasi Fakultas Ilmu Keolahragaan Universitas Negeri Padang 
karena hal itu penulis ingin mengenalkan permainan bola besar yang sudah dikembangkan oleh dosen Fakultas Ilmu Keolahragaan Universitas Negeri Padang. Permainan ini merupakan pengembangan dari beberapa cabang olahraga lain, yaitu sepakbola, bolavoli, dan sepaktakraw. Oleh sebab itu permainan ini diberi nama "Volscert". Volscert merupakan permainan beregu dan merupakan permainan kontak tidak langsung. Hal itu dikarenakan permainan ini mengambil konsep seperti permainan bolavoli dimana masing masing regu memiliki lapangan sendiri dan dibatasi oleh net atau jaring. Pola permainan yang ada dalam permainan ini mengadaptasi dari tiga cabang olahraga yaitu bolavoli, sepakbola dan sepaktakraw. Proses penyerangan harus dilakukan dengan kaki sedangkan bertahan boleh menggukan tangan seperti dalam permainan bolavoli

Permainan ini sangat cocok dimainkan oleh remaja dan pemuda karena dari model permainannya sangat baik untuk mengolah tubuh. Hal itu dikarenakan semua anggota gerak tubuh dapat digunakan untuk melakukan permainan. Dengan konsep permainan yang demikian, olahraga ini juga sangat baik untuk merangsang kinerja otak para siswa. Siswa dituntut untuk berfikir kapan harus menggukana tangan dan kapan harus menggukan kaki agar tidak melanggar peraturan. Para pemain juga harus lihai dalam membaca situasi agar dapat memasukan bola ke daerah permainan lawan.Permainan ini juga melibatkan kontrol tubuh, karena dalam melakukan permainan atlet harus bisa mengontrol bola agar dapat melakukan penyerangan yang baik.

Permainan volscert ini tergolong permainan yang sangat baru oleh karena itu butuh pengembangan dan pengenalan terhadap siswa- siswa disekolah. Untuk melihat tingkat keberterimaan siswa terhadap olahraga ini maka dilaksanakan penelitian disekolah sekolah. Hasil yang didapat diharapkan bisa menjadi referensi siswa untuk berolahraga dalam rangka mengembangkan kemampuan fisik dan motorik.

\section{METODOLOGI}

Penelitian ini merupakan jenis penelitian deskriptif, yaitu penelitian yang tidak bermaksud untuk menguji hipotesis tertentu tetapi hanya menggambarkan apa adanya tentang sesuatu variabel, gejala atau keadaan (Arikunto, 2010:3) Dengan demikian penelitian ini akan mengungkapkan data yang ditemui di lapangan yaitu tentang tingkat 7) Alfio Restu Fernando. Saat ini Mahasiswa Jurusan Kesehatan dan Rekreasi Fakultas Ilmu Keolahragaan Universitas Negeri Padang

7) M. Sazeli Rifki. Saat ini Dosen Jurusan Kesehatan dan Rekreasi Fakultas Ilmu Keolahragaan Universitas Negeri Padang

${ }^{7)}$ Endang Sepdanius. Saat ini Dosen Jurusan Kesehatan dan Rekreasi Fakultas Ilmu Keolahragaan Universitas Negeri Padang 
keberterimaan siswa sekolah menengah atas di Kecamatan Padang Utara Kota Padang terhadap permainan volscert. Populasi dalam penelitian ini adalah seluruh siswa sekolah mengah atas di Kecamatan Padang Utara Kota Padang sebanyak 7 sekolah berjumlah 3251 siswa. Sampel dalam penelitian ini diambil dengan teknik random sampling yang berjumlah 118 orang siswa dari dua sekolah yang terpilih yaitu SMAN 1 Padang dan SMAN 3 Padang.

\section{Prosedur pelaksanaan}

Siswa diberi buku panduan permainan volscert terlebih dahulu untuk dipahami, kemudian setelah itu siswa diajak untuk melaksanakan permainan. Selama pelaksanaan permainan volscert siswa diperbolehkan untuk bertanya tentang peraturan permainan. Setelah pelaksanaan permainan peserta diberik angket penilaian siswa terhadap permainan volscert. Angket ini digunakan untuk menilai tingkat keberterimaan siswa terhadap permainan volscert.

\section{Instrumen penelitian}

Intrumen penelitian yang digunakan adalah angket keberteriamaan yang terdiri dari skala 1-5 dimana responden diberikan alternative jawaban dan diminta untuk memilih jawaban yang tersedia. Adapun aspek yang adalah aspek kemudahan memahami permainan, aspek keamanan dan kemudahan penggunaan peralatan serta aspek kemudahan dalam memahami peraturan permainan, selain itu, angket juga melihat aspek keterbacaan, aspek kejelasan isi, dan aspek kemenarikan buku peraturan permainan

\section{Analisis Data}

Setelah hasil data di lapangan dikumpulkan selanjutnya dilakukan pengolahan data berdasarkan data yang terkumpul dan telah memenuhi syarat untuk di analisa. Teknik analisa data dilakukan dengan menggunakan tabulasi frekuensi dan rata-rata (A. Muri Yusuf 2005)

\section{HASIL DAN PEMBAHASAN}

Analisis data tentang tingkat keberterimaan siswa sekolah menengah atas di Kecamatan Padang Utara terhadap olahraga volscert adalah sebagai berikut: Distribusi frekuensi data keseluruah tingkat keberterimaan siswa sekolah menengah atas terhadap olahraga volscert di SMA N 1 Padang padat dilihat pada tabel 1

7) Alfio Restu Fernando. Saat ini Mahasiswa Jurusan Kesehatan dan Rekreasi Fakultas Ilmu Keolahragaan Universitas Negeri Padang

7) M. Sazeli Rifki. Saat ini Dosen Jurusan Kesehatan dan Rekreasi Fakultas Ilmu Keolahragaan Universitas Negeri Padang

${ }^{7)}$ Endang Sepdanius. Saat ini Dosen Jurusan Kesehatan dan Rekreasi Fakultas Ilmu Keolahragaan Universitas Negeri Padang 
Tabel 1. Distribusi Frekuensi Data siswa SMA N 1 Padang

\begin{tabular}{cclc}
\hline Interval & F & \multicolumn{1}{c}{ Kategori } & F relatif \% \\
\hline $\mathbf{7 7}-\mathbf{1 3 8 , 6}$ & 1 & Sangat tidak baik & $1.72 \%$ \\
\hline $\mathbf{1 3 8 , 7}-\mathbf{2 0 0 , 3}$ & 0 & Tidak baik & $0 \%$ \\
\hline $\mathbf{2 0 0 , 4 - \mathbf { 2 6 2 , 0 }}$ & 5 & Ragu-ragu & $8.62 \%$ \\
\hline $\mathbf{2 6 2 , 1 - 3 2 3 , 7}$ & 24 & Baik & $41.38 \%$ \\
\hline $\mathbf{3 2 3 , 8}-\mathbf{3 8 5}$ & 28 & Sangat Baik & $48.28 \%$ \\
\hline Total & 58 & & $100 \%$ \\
\hline
\end{tabular}

Secara keseluruhan dari hasil analisis data angket didapat kan hasil tingkat keberterimaan siswa sekolah menengah atas di Kecamatan Padang utara terhadap olahraga volscert di SMA N 1 Padang adalah sebanyak 28 orang dari 58 siswa menyatakan sangat baik atau $48 \%$ dan 24 orang menyatakan baik atau $41 \%$.
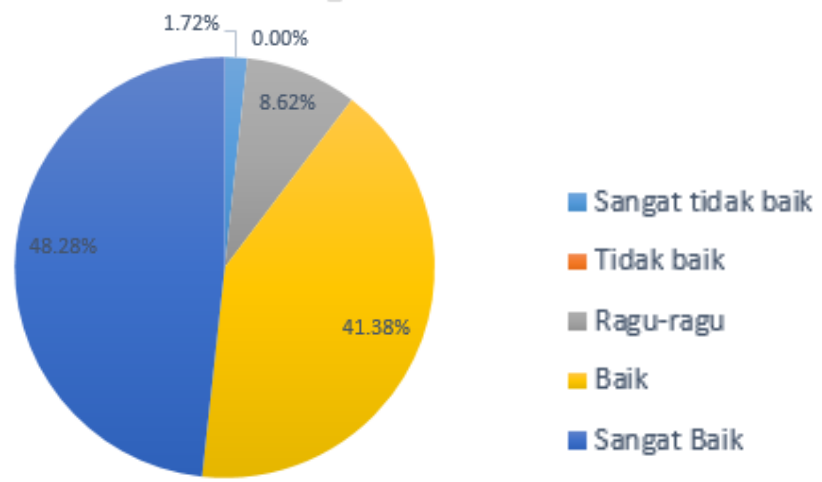

Gambar 1. Histogram Distribusi Frekuensi Data siswa SMA N 1 Padang

Distribusi frekuensi data keseluruah tingkat keberterimaan siswa sekolah menengah atas terhadap olahraga volscert di SMA N 1 Padang padat dilihat pada tabel 2.

Tabel 2. Distribusi Frekuensi Data siswa SMA N 3 Padang

\begin{tabular}{cclc}
\hline Interval & F & \multicolumn{1}{c}{ Kategori } & F relatif \% \\
\hline $\mathbf{7 7 - 1 3 8 , 6}$ & 0 & Sangat tidak Baik & $0 \%$ \\
\hline $\mathbf{1 3 8 , 7 - 2 0 0 , 3}$ & 0 & Tidak Baik & $0 \%$ \\
\hline $\mathbf{2 0 0 , 4 - 2 6 2 , 0}$ & 2 & Ragu-ragu & $3.33 \%$ \\
\hline $\mathbf{2 6 2 , 1 - 3 2 3 , 7}$ & 31 & Baik & $51.67 \%$ \\
\hline $\mathbf{3 2 3 , 8}-\mathbf{3 8 5}$ & 27 & Sangat Baik & $45 \%$ \\
\hline Total & 60 & & $100 \%$ \\
\hline
\end{tabular}

Hasil analisis data SMA N 3 Padang didapatkan hasil sebanyak 27 orang dari 60 siswa menyatan sangat baik atau $45 \%$ dan 31 orang menyatakan baik atau $51.67 \%$.

7) Alfio Restu Fernando. Saat ini Mahasiswa Jurusan Kesehatan dan Rekreasi Fakultas Ilmu Keolahragaan Universitas Negeri Padang

7) M. Sazeli Rifki. Saat ini Dosen Jurusan Kesehatan dan Rekreasi Fakultas Ilmu Keolahragaan Universitas Negeri Padang

${ }^{7)}$ Endang Sepdanius. Saat ini Dosen Jurusan Kesehatan dan Rekreasi Fakultas Ilmu Keolahragaan Universitas Negeri Padang 


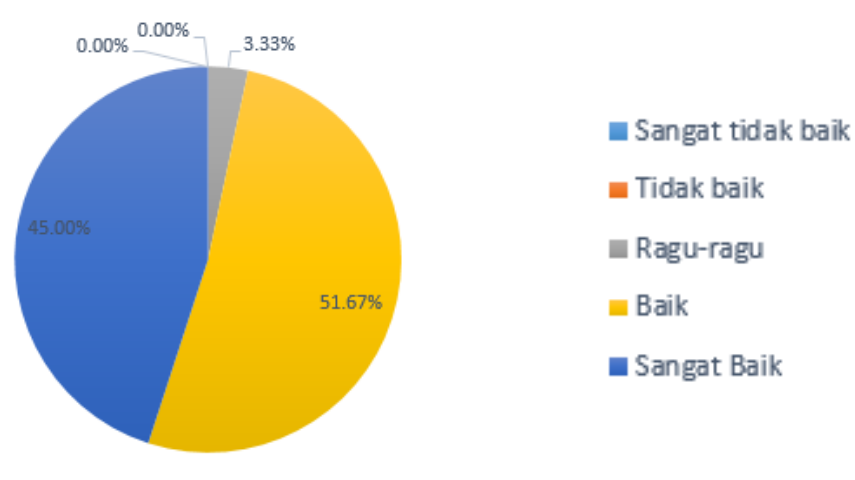

\section{Gambar 1. Histogram Distribusi Frekuensi Data siswa SMA N 3 Padang}

Penilaian siswa terhadap peraturan dalam permainan volscert berdasarkan angket yang dibagikan menunjukan bahwa sebanyak $47 \%$ menyatakan baik bahwa peraturan volscert memberikan kejelasan bentuk peraturan permainan seperti, cara melakukan servis, pasing, bertahan, dan melakukan penyerangan karena dengan mengetahui hal tersebut siswa dapat memahami cara melakukan permainan volscert dengan baik.

Penilaian siswa pada perwasitan dalam permainan volscert menunjukan bahwa $46 \%$ responden menilai baik dengan perwasitan pemainan volscert. Peran wasit sangat penting untuk membuat permainan berjalan adil dan sesusai dengan peraturan yang telah dijelaskan. Kejelasan instruksi wasit juga mempengaruhi jalannya permainan.Wasit juga menjadi tempat bertanya oleh siswa untuk melakukan permainan volscert dengan baik. Sehingga ketika bermain siswa tidak salah dalam menjalankan peraturan agar permianan berjalan dengan baik dan adil.

Sebanyak $49 \%$ responden menilai sangat baik terhadap perlengkapan permainan volscert. Dari hasil angket yang didapat dapat dilihat bahwa perlengkapan dalam permainan volscert memadai untuk melakukan permainan volscert. Utamanya adalah ketersediaannya lapangan permainan. Pada sampel yang diteliti, sekolah memiliki sarana dan prasarana yang baik untuk olahrga. Adanya lapangan olahraga dan pelengkapan seperti tiang net memudahkan peneliti untuk mengenalkan olahraga volscert kepada siswa. Sehingga keberadaan lapangan volscert sangat memungkinkan untuk dikondisikan pada daerah yang memiliki lapangan bolavoli, lapangan sepaktakraw dan lapangan lainnya yang memungkinkan memiliki luas yang dibutuhkan untuk menggelar permainan volscert.

7) Alfio Restu Fernando. Saat ini Mahasiswa Jurusan Kesehatan dan Rekreasi Fakultas Ilmu Keolahragaan Universitas Negeri Padang

7) M. Sazeli Rifki. Saat ini Dosen Jurusan Kesehatan dan Rekreasi Fakultas Ilmu Keolahragaan Universitas Negeri Padang

${ }^{7)}$ Endang Sepdanius. Saat ini Dosen Jurusan Kesehatan dan Rekreasi Fakultas Ilmu Keolahragaan Universitas Negeri Padang 
Berikut disajikan ringkasan tentang permainan volscert yang telah dikembangkan oleh Sazeli Rifki:

\section{Bola}

Dari sepesifikasi tiga bola dari cabang olahraga sepakbola, bolavolley dan sepaktakraw maka dikembangkanlah sebuah bola yang dapat dimainkan dengan sempurna pada model olahraga yang dikembangkan ini (untuk selanjutnya akan diberi nama volscert).

Tabel 3. Spesifikasi Volscert

\begin{tabular}{|l|l|}
\hline Spesifikasi & Volscert \\
\hline Keliling & $57-60 \mathrm{~cm}$ \\
\hline Berat bola & 290 gram sampai 300 gram \\
\hline Tekanan & $0,6-1,1$ atm $(600-1100 \mathrm{~g} / \mathrm{cm} 2)$ \\
\hline Bahan & Terbuat dari bahan karet lembut \\
\hline
\end{tabular}

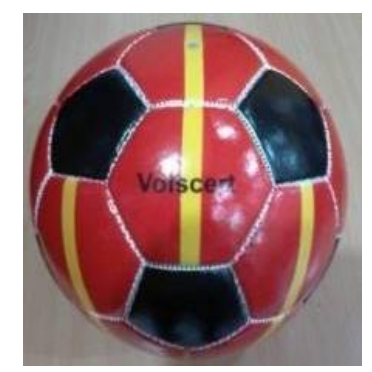

Gambar 3. Bola Volscert

\section{Net}

Dari spesifikasi ini dilakukan modifikasi peralatan yang nantinya bisa digunakan untuk bermain dalam permainan volscert. Adapun spesifikasi dari net dan tiang net dari permainan volscert ini sebagai berikut:

\section{Tabel 5. Spesifikasi Tiang Net dan Net olahraga Volscert}

\begin{tabular}{|l|l|}
\hline Spesifikasi & Volscert \\
\hline Tinggi Net & $\begin{array}{l}\text { Tinggi net untuk putra pada lapangan permainan bola } \\
\text { volscert memiliki ukuran tinggi net 1,55m dipinggir dan } \\
\text { minimal 1,52 di bagian tengah. Putri: Tinggi net 1,45m } \\
\text { dipinggir dan minimal 1,42 di bagian tengah. }\end{array}$ \\
\hline Posisi Net & $\begin{array}{l}\text { Jarak antara tiang net dengan garis yang berada di samping } \\
\text { lapangan permainan bola volscert memiliki ukuran yaitu } 0,5 \\
\text { sampai 1 meter }\end{array}$ \\
\hline Lebar sel & $4-6 \mathrm{~cm}$ \\
\hline
\end{tabular}

7) Alfio Restu Fernando. Saat ini Mahasiswa Jurusan Kesehatan dan Rekreasi Fakultas Ilmu Keolahragaan Universitas Negeri Padang

7) M. Sazeli Rifki. Saat ini Dosen Jurusan Kesehatan dan Rekreasi Fakultas Ilmu Keolahragaan Universitas Negeri Padang

${ }^{7)}$ Endang Sepdanius. Saat ini Dosen Jurusan Kesehatan dan Rekreasi Fakultas Ilmu Keolahragaan Universitas Negeri Padang 


\section{Bentuk lapangan}

Agar bisa bermain permainan volscert dibutuhkan area berukuran lebih kurang $20 \mathrm{x} 10$ meter terdiri dari area lapangan dan area bebas. Adapun spesifikasi dari bentuk lapangan adalah sebagai berikut: (1) Lapangan permainan berbentuk persegi panjang dengan ukuran 14 meter x 7 meter dikelilingi daerah bebas disemua sisi sejauh 3 meter. (2) daerah permainan harus memiliki ketinggian minimum 10 meter. (3) lapangan memiliki garis bebas di sisi belakang untuk melaksanakan servis. (4) Lapangan dibagi menjadi dua buah sisi dan dibatasi oleh net. (5) Satu sisi dibagi menjadi dua bahagian menjadi area penyerangan dan area bertahan. (6) Area bertahan memiliki luas 4 meter x 7 meter dari garis belakang kearah net. (7) Area penyerang memiliki luar 3 meter x 7 meter dari garis net ke arah belakang. (8)Garis servis memanjang daris sisi lapangan dengan panjang 2 meter dari garis batas belakang. Untuk lebih jelasnya dapa dilihat pada gambar berikut:

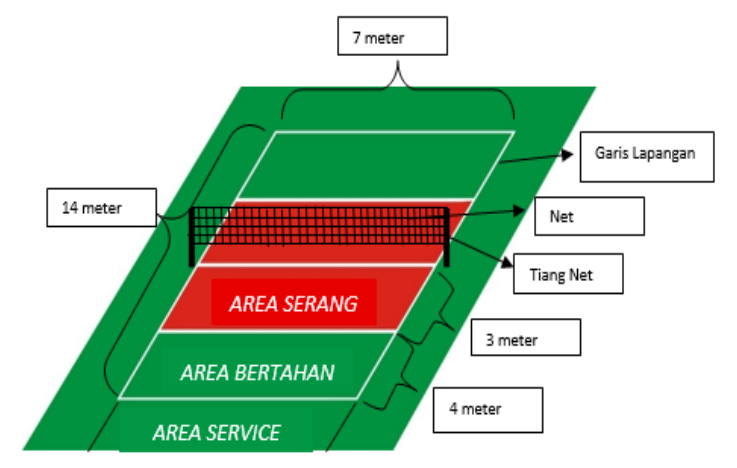

Gambar 4. Lapangan Volscert

\section{Permukaan lapangan}

Permukaan lapangan permainan volscert dideskripsikan sebagai barikut: (1) Lapangan permainan harus datar, horizontal dan seragam. (2) Lapangan tidak boleh menimbulkan bahaya terhadap pemain. (3) Lapangan tidak diperkenan dibuat pada daerah yang tidak datar. (4) Lapangan boleh dibuat pada dasar pasir, rumput, lantai dan karet.

\section{Garis lapangan}

Adapun deskripsi dari lapangan volscert adalah (1) Garis lapangan memiliki lebar $5 \mathrm{~cm}$,

(2) Garis harus berwarna terang dan memiliki warna berbeda dari warna lapangan. (3)

Lapangan permainan ditandai dengan dua garis samping dan dua garis akhir. (4) Dalam lapangan terdapat garis tengah yang membagi lapangan menjadi dua ( $7 \mathrm{~m} \times 7 \mathrm{~m})$. (5)

Setiap sisi terbagi lagi dengan garis serang dengan panjang $3 \mathrm{~m}$ dari gari tengah lapangan

7) Alfio Restu Fernando. Saat ini Mahasiswa Jurusan Kesehatan dan Rekreasi Fakultas Ilmu Keolahragaan Universitas Negeri Padang

7) M. Sazeli Rifki. Saat ini Dosen Jurusan Kesehatan dan Rekreasi Fakultas Ilmu Keolahragaan Universitas Negeri Padang

${ }^{7)}$ Endang Sepdanius. Saat ini Dosen Jurusan Kesehatan dan Rekreasi Fakultas Ilmu Keolahragaan Universitas Negeri Padang 


\section{Service}

Servis dilakukan sebagai berikut: (1) Pemain akan memulai permainan dengan melakukan service pada area servis yang berada di belakang garis belakang. (2) Service dilakukan dengan menggunakan alat gerak bagian bawah. (3) Bola ditendang dengan anggota gerak bawah sesaat bola sudah terbebas dari tangan. (4) Pemain tidak boleh menginjak garis batas belakang sebelum bola yang diservis melewati net. (5) Service dinyatakan sah apabila bola bisa melewati net dan tidak keluar dari lapangan atau menyentuh garis lapangan. (6) Bola servis jika mengenai net dan melewati net kemudian masuk ke lapangan lawan tetap dianggap sah. (7) Servis hanya dilakukan satu kali setiap tim (8) Servis dikatakan gagal bila: (a) bola tidak melewati net (tersangkut), (b) orang yang melaksanakan servis masuk kelapangan melewati garis belakang sebelum bola berpindah kelapangan lawan melewati net, (c) bola keluar lapangan

\section{Area permainan}

Area permainan volscert dibagi menjadi dua yaitu area serang dan area belakang. Pemain yang berada pada area serang boleh melakukan smash. Pemain yang berada di area belakang boleh melakukan pasing menggunakan tangan di daerah belakang dan tidak boleh menggunakan tangan pada daerah serang. Pemain belakang boleh menyebrangkan bola hanya menggunakan kaki. Pemain pada posisi area serang tidak boleh berpindah ke posisi bertahan sebelum bola servis dari lawan melewati net. Pemain pada posisi bertahan tidak boleh berpindah ke posisi area serang sebelum bola servis dari lawan melewati net. Perubahan posisi setiap pemain diawali dengan pertambahan poin. Perubahan posisi pemain mengikuti arah jarum jam. Pemain tidak boleh menyentuh bola sebanya dua kali menggunakan tangan. Pemaina hanya boleh melakukan blok pada net menggunakan anggota tubuh kecuali tangan.

\section{KESIMPULAN}

Berdasarkan hasil analisis data penelitian dan pembahasan, maka diperoleh kesimpulan tingkat keberterimaan siswa sekolah menengah atas di Kecamatan Padang Utara terhadap olahraga volscert termasuk dalam kategori baik. Semua asepk Indikator dalam penilian dijawab oleh siswa sesuai dengan apa yang telah dilaksanakan. Oleh sebab itu,

7) Alfio Restu Fernando. Saat ini Mahasiswa Jurusan Kesehatan dan Rekreasi Fakultas Ilmu Keolahragaan Universitas Negeri Padang

7) M. Sazeli Rifki. Saat ini Dosen Jurusan Kesehatan dan Rekreasi Fakultas Ilmu Keolahragaan Universitas Negeri Padang

${ }^{7)}$ Endang Sepdanius. Saat ini Dosen Jurusan Kesehatan dan Rekreasi Fakultas Ilmu Keolahragaan Universitas Negeri Padang 
permainan volscert dapat diterima dengan baik oleh siswa sekolah menengah atas sebagai pilihan lain untuk melakukan olahraga.

\section{REFERENSI}

A. Sarumpaet, Dkk. 1992. Permainan Besar. Padang: Fakulta Ilmu Keolahragaan Universsitas Negeri Padang

Arikunto, Suharsini. 2010. Prosedur Penelitian. Bina Angkasa: Jakarta

Dimyati \& Mudjiono. 2006. Belajar dan Pembelajaran. Jakarta: PT. Rineka Cipta.

Dwiyogo.W.D. 2010.Dimensi Teknologi Pembelajaran Pendidikan Jasmani dan

Olahraga. Malang: Wineka Media

Hevarianto. Akhmad A. 2013. Penilaian Pelatih Dan Pengawasan Pertandingan

Terhadap Kinerja Wasit PSSI Sidoarjo.Universitas Negeri Surabaya.

Husdarta. H. 2009. Manajemen Pendidikan Jasmani. Bandung: Alfabeta.

Sazeli Rifki, Dkk. 2017. Draft Permainan Volscert. Fakultas ilmu Keolahragaan. Universitas Negeri Padang.

Sugiyono, 2009, Metode Penelitian Kuantitatif, Kualitatif dan R\&D, Bandung: Alfabeta.

7) Alfio Restu Fernando. Saat ini Mahasiswa Jurusan Kesehatan dan Rekreasi Fakultas Ilmu Keolahragaan Universitas Negeri Padang

7) M. Sazeli Rifki. Saat ini Dosen Jurusan Kesehatan dan Rekreasi Fakultas Ilmu Keolahragaan Universitas Negeri Padang

${ }^{7)}$ Endang Sepdanius. Saat ini Dosen Jurusan Kesehatan dan Rekreasi Fakultas Ilmu Keolahragaan Universitas Negeri Padang 